\title{
Birth outcome and correlates of low birth weight and preterm delivery among infants born to HIV-infected women in public hospitals of Northwest Ethiopia
}

\author{
Bekana Kebede $^{1 \#}$, Gashaw Andargie ${ }^{1}$, Abebaw Gebeyehu $^{2}$ \\ ${ }^{1}$ Department of Health Services Management, Institute of Public Health, University of Gondar, Gondar, Ethiopia; \\ \#Corresponding Author: bekanasiif@gmail.com \\ ${ }^{2}$ Department of Reproductive Health, Institute of Public Health, University of Gondar, Gondar, Ethiopia
}

Received 7 May 2013; revised 8 June 2013; accepted 30 June 2013

Copyright (C) 2013 Bekana Kebede et al. This is an open access article distributed under the Creative Commons Attribution License, which permits unrestricted use, distribution, and reproduction in any medium, provided the original work is properly cited.

\begin{abstract}
Background: HIV-positive pregnant women are at an increased risk of adverse pregnancy outcomes. However, data on birth outcome among HIV-infected women are limited in Ethiopia. This study was conducted to identify the adverse birth outcomes and associated factors of low birth weight (LBW) and preterm delivery (PD) among HIV-infected women. Methods: A hospital based retrospective cohort study was conducted. All deliveries from HIV-infected women from September 1, 2009 to April 30, 2012 were included in the study. Multivariate logistic regression was performed to explore the potential risk factors for LBW and PD. Result: Out of $\mathbf{4 1 6}$ singleton infants born to HIV-infected mothers, the prevalence of LBW and PD was 89 (21.4\%) and $69(16.6 \%)$, respectively. The baseline maternal CD4 counts below 200 cells $/ \mathrm{mm}^{3}$, maternal body mass index (BMI) below 18.5, maternal anemia and maternal exposure to Highly Active Antiretroviral Treatment (HAART) were factors significantly associated with LBW. On the other hand, a baseline maternal CD4 level below $200 / \mathrm{mm}^{3}$, having no Prevention of Mother-to-Child Transmission (PMTCT) intervention during pregnancy, maternal BMI less than 18.5, maternal Eclamsia
\end{abstract}

\footnotetext{
*Competition of interest: We declare that there is no competition of interest.

Contribution of authors: BK conceived, developed the proposal, designed, involved in data collection, processed, analyzed, wrote, drafted and re-edited the manuscript. GA was involved in revising and approving of the proposal, reviewing of the analysis and interpretation of the result and revised the manuscript. AG was involved in revising the proposal and design of the study, involved in the statistical analysis and interpretation, revised the manuscript.
}

during pregnancy, and mothers being on HAART before pregnancy were factors associated with preterm delivery. Conclusion: There was a significant prevalence of low birth weight and preterm delivery among infants born to HIV-positive mothers. The programme for PMTCT services should maximize the need for an early identification of those mothers with predicted complications.

Keywords: HIV; Pregnancy; Birth; Infant; Mother; Ethiopia

\section{BACKGROUND}

HIV continues to be a burden on women and children worldwide [1]. In 2008, out of 33.4 million individuals living with HIV, 15.7 million were women [1,2]. Currently, about 3 million people are estimated to be receiving antiretroviral therapy (ART) in low and middle-income countries out of which $56 \%$ are women [1]. In $2011,92 \%$ of pregnant women living with HIV resided in sub-Saharan Africa [3].

Ethiopia is one of the countries having a large number of HIV-infected people in Africa with national adult prevalence of $2.1 \%$. Women have a higher HIV prevalence $(1.9 \%)$ than men, and over $8 \%$ of pregnant women are estimated to be living with HIV [4,5]. In 2009, there were an estimated 84,189 HIV-positive pregnancies and 14,093 HIV-positive births [6,7]. According to the recent five-year national level PMTCT data analysis, 53\% of the known HIV-positive mothers and $48 \%$ of the known HIV-exposed infants have received antiretroviral (ARV) prophylaxis [7].

HIV infection in pregnancy has become the most common complication of pregnancy. The WHO guideline 
now recommends the initiation of HAART in pregnancy and the PMTCT options for all HIV-infected pregnant women to maximize the prevention of HIV transmission and maternal and infant survival $[8,9]$. About $53 \%$ of the estimated HIV-infected pregnant women worldwide received at least some ARV drugs to prevent HIV transmission to their baby in 2009 [10]. Early HAART initiation for all HIV-positive pregnant women [2,11] and a widespread use of HAART among HIV-infected pregnant women have led to significant decreases in HIV transmission to the infant $[12,13]$ and decreases in maternal morbidity [14-16].

The PMTCT program in Sub-Saharan African countries takes different forms currently. It includes zidovudine (AZT) and lamivudine (3TC) during the final weeks of pregnancy and single dose nevirapine(sd-NVP) at delivery $[2,9,17]$. As of the $2007 / 8$ Ethiopian PMTCT guideline, HIV infected women who become pregnant while receiving HAART were advised to continue during pregnancy, labour and post partum. All pregnant HIV-positive women were evaluated for ART eligibility using immunological and clinical criteria; and accordingly, eligible mother presented during the first 12 weeks of pregnancy were started with ART if the mother had advanced HIV infection or a CD4 count was $<200$ cells $/ \mathrm{mm}^{3}$, otherwise the treatment was delayed until 28 weeks of gestation. On the other hand, short course ARV prophylaxis was recommended after 28 weeks of gestation for those not eligible for ART. The ART programme was mainly in accordance with the WHO recommendations, which were mainly combinations of first line regimens, and the prophylaxis included zidovudine (AZT) and lamivudine (3TC) [18]. However, the new 2011 PMTCT guideline has revised the initiation of ART for all HIVpositive pregnant women if their CD4 count is below 350 cells $/ \mathrm{mm}^{3}$ [6].

However, HIV infection and the use of such medications during pregnancy may result in adverse infant birth outcome. Also many uncertainties remain regarding the potential adverse effects of HAART initiation and its use in pregnancy in addition to the burden of the disease itself. Early infant mortality, LBW and PD are the commonly reported adverse outcomes among HIV-infected women [16].

The risk of facing adverse infant birth outcome was associated with maternal CD4 level, duration and time of HAART initiation, and type of HAART regimens according to many previous studies from Africa and Europe [19-21]. But still there remain controversies between different studies in different countries [22-24].

PD and LBW are the most common direct causes of newborn mortality. According to World Health Organization (WHO) definition, LBW is defined as weight of newborn less than $2.5 \mathrm{~kg}$ measured within the first hours of life, and PD is defined as birth of infant at less than 37 weeks of complete gestation. According to the epidemiological observations, infants with LBW are approximately 20 times more likely to die than heavier babies [25]. More than 20 million infants worldwide, representing 15.5 percent of all births, are born with LBW, 95.6 percent of whom are in developing countries. LBW contributes from $60 \%$ to $80 \%$ of all neonatal deaths [26].

However, as such data on PMTCT and treatment outcomes are limited in Ethiopia, the main aim of this study was to identify adverse infant birth outcome and associated factors of LBW and PD among infants born to HIVinfected mothers.

\section{METHODS}

\subsection{Study Design and Population}

A hospital based retrospective cohort study design was conducted, for which recorded data of infant-mother pairs were obtained from deliveries to HIV-positive women using data extraction format. The study was conducted in the three public hospitals of North Gondar Zone, Amhara region, Ethiopia, namely; Gondar University Hospital, Metema Hospital and Debark Hospital (Figure 1).

In this region, the estimated HIV prevalence among the population aged $15-49$ is $2.2 \%$. About $10.2 \%$ of deliveries were attended in health facilities in the general population, and the neonatal mortality rate was 54/1000 live births, as of the 2011 Ethiopian demographic and health survey [5].

Metema and Debark hospitals are currently the only two district Public hospitals in the North Gondar Zone. Both of them are providing services to more than 50,000 populations in their catchment area, and on average about 500 deliveries are attended in the hospital per year, according to the hospitals report. The hospitals in addition to providing full obstetric/delivery services; they refer complicated cases especially requiring surgical interventions, to the Gondar University Hospital.

Gondar University Hospital is the referral and teaching hospital in the region, which is serving about 6 million people in the catchment area, and nearly 100,000 patient visits are recorded at the outpatient clinics. In addition to that, approximately 2000 deliveries are attended every year at this hospital, according to the hospital report. All the three hospitals are providing full ANC/PMTCT, ART, delivery services and ultrasound guided obstetric cares.

All infants born to HIV-infected women at the hospitals from September 1, 2009, to April 30, 2012, were included in the study. Twin births and incomplete or not available mother-infant birth outcome records were excluded from the study. Incomplete or not available motherinfant birth outcome is where the infant birth outcomes 


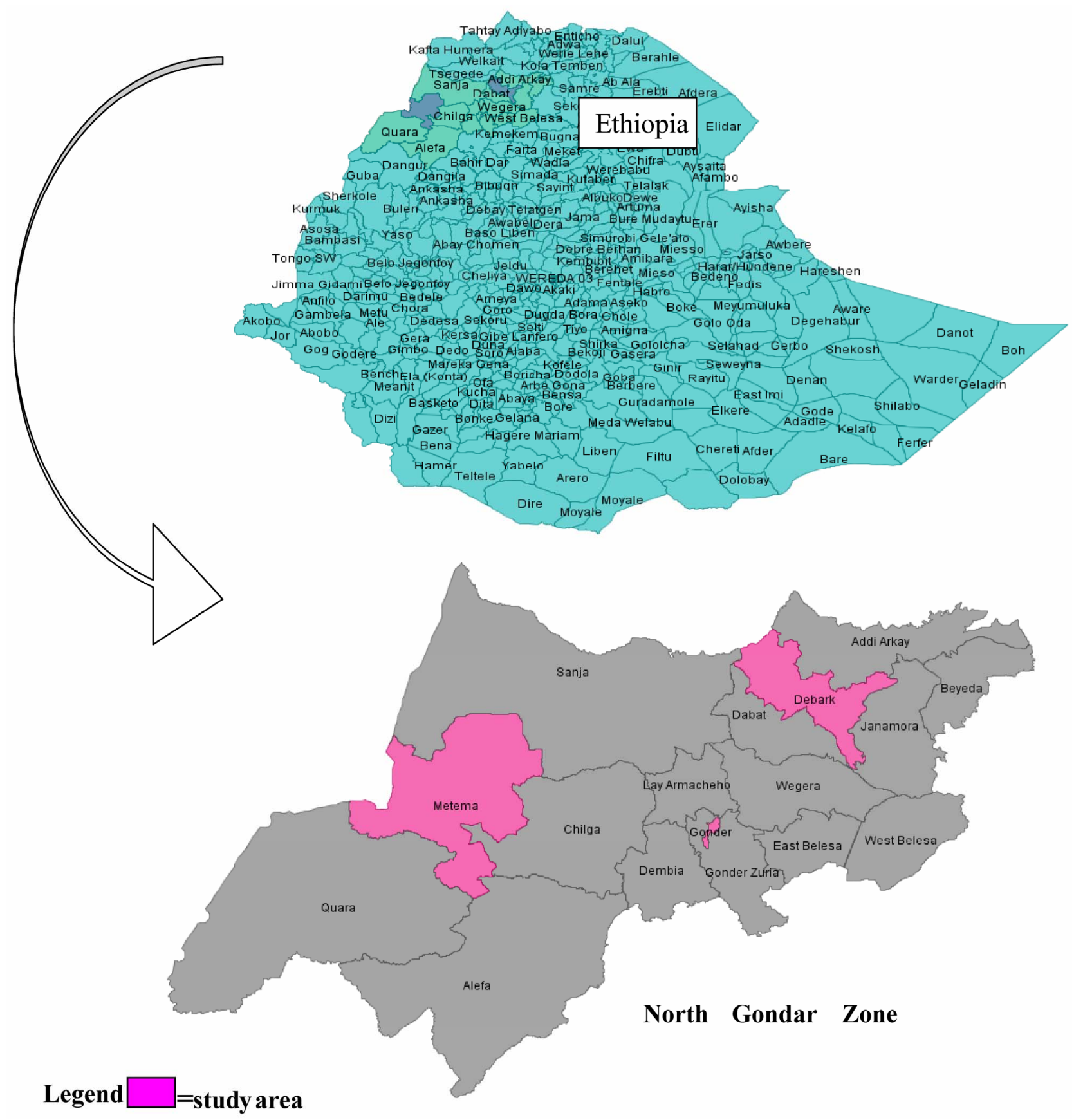

Figure 1. Study area (Gondar, Metema and Debark Hospitals) in North Gondar, Ethiopia.

from the HIV-positive mother were not recorded or the mother's data are not available totally.

\subsection{Data Collection Procedures}

The data extraction format was initially pretested and checked for completeness or content and feasibility. The data collection was initially started by abstracting data from delivery outcome record of HIV-positive women on all information including the infant birth weight, gestational age at birth, maternal characteristics including
PMTCT intervention. After the delivery record informations obtained, the maternal ANC/PMTCT and ART follow-up related data were collected. The mothers' ANC/ PMTCT record was used to collect informations or characteristics including socio-demographic, maternal weight and enrollment BMI, current and previous obstetric history, and antiretroviral treatment history during ANC follow-up at the ART clinic and during delivery. Pre-ART and ART follow-up informations of the clients were electronically documented (in Debark and Gondar hospitals). 
The original data in the health institution were completed by medical doctors and nurses during the follow-up of mothers. Maternal BMI was determined by using the mother's prepregnancy, initial weight and height from their ART/pre-ART and PMTCT follow-up. Gestational age used was that of determined by clinicians during the women antenatal visit and/or during delivery using a combination of ultrasound (when available), last menstrual period (LMP) and symphyseal fundal height examination (FHE). Newborn weight was measured using standard beam balance within the first hour of birth.

The data were abstracted by both trained data collection assistants and the investigator with the help of hospital record officers, and the data quality or completeness was checked each time the data obtained.

\subsection{Ethical Consideration}

The study was ethically approved by the Ethical Review Board of the Institute of Public Health, College of Medicine and Health Sciences, the University of Gondar. Permission was obtained from the medical director of each hospital. As it was an anonymous database review no individual patient consent was deemed necessary. Personal information remained confidential and personal practices were not identified.

\subsection{Data Analysis}

Data was entered into the Epi Info version 3.5.3 and transported to the SPSS statistical soft ware version 20.0; and data was coded, entered, cleaned and analyzed using the SPSS.

The maternal informations analyzed were demographic characteristics, obstetric history, HIV disease status, ARV use history including CD4 cell count and WHO clinical stage of the disease. The infant birth outcomes analyzed into logistic regression were Low Birth Weight $(<2500 \mathrm{~g})$ and Preterm Delivery (gestational age $<37$ weeks). For variables with some missing values the sensitivity test was done after performing multiple imputations. Multivariate Logistic regression analysis was performed to explore the potential risk factors separately for both LBW and PD. All variables in the Univariate analysis with a $P$ value of less than 0.2 were entered into multivariate models using the stepwise logistic regression. Variables were held in the models if they reached a significance level of $\mathrm{P}$ value $<0.05$. The odds ratio and $95 \%$ confidence intervals were also constructed along with their corresponding $p$ values.

\section{RESULT}

\subsection{Baseline Maternal Socio-Demographic and Disease Characteristics}

A total of 416 babies of HIV-infected women born in the hospitals were included in the study. The mean age of the mothers was 27.27 [ \pm 4.5$]$. Majority, 360 (86.5\%) were from urban and about half of the mother were housewives. While 181 (45.7\%) of mothers were uneducated, $103(25.7 \%)$ and $84(20.7 \%)$ attended primary and secondary school education, respectively. A total of 262 $(63 \%)$ were married and $76(18.3 \%)$ of the mothers were divorcees.

Majority, 346 (83.2\%) deliveries were spontaneous, and only $8.6 \%$ of the labor was induced. The mean pregnancy weight gain was 7.6 with $\pm 3.4 \mathrm{SD}$ and the mean BMI of mothers was 20.5 with+2.58SD. Only about 8 $(1.9 \%)$ and $4(1 \%)$ of the mothers had history of HTN and DM during pregnancy (Table 1).

The maternal baseline median CD4 count level was 337 (IQR 84-762) cells $/ \mathrm{mm}^{3}$. A total of 200 (48.07\%) of mothers were on HAART, and $130(31.25 \%)$ were on pre-ART, who are given PMTCT prophylaxis during pregnancy, and the rest had no PMTCT intervention. In addition, $77(38.5 \%)$ of those on HAART had baseline CD4 count of less 200 cells $/ \mathrm{mm}^{3}$.

\subsection{Infant Birth Outcome}

Out of the 416 infants born to HIV-infected mothers, $377(90.6 \%)$ were alive at birth, until discharge from hospital. There were $9(2.2 \%)$ still births and $4(1.0 \%)$ congenital malformations; and 24 cases of newborns were died within the period of birth to stay in hospital, making the rate of 58/1000 live births.

This study revealed that the prevalence of low birth weight (LBW) was found to be 89 (21.4\%).

The mean birth weight of the newborns was $2.7 \mathrm{~kg}$ $[ \pm 0.45 \mathrm{~kg}]$. On the other hand, the prevalence of preterm delivery (PD) was 69 (16.6\%).

Compared to infants born to HIV-infected mother who were not exposed to HAART, the prevalence of LBW was significantly higher among those infants of HIV-infected mother who were exposed to HAART on pregnancy $(5.6 \%$ vs $38.5 \%$ ). Similarly, Infants of HIV-infected women who were enrolled in PMTCT (either HAART or Prophylaxis), had lower risk of PD compared to their counterparts (11.6\% vs 23.9\%) (Figure 2).

There was a significantly higher proportion of LBW and PD among those mothers with a CD4 level below 200 cells $/ \mathrm{mm}^{3}$ as compared to those with over 350 cells/ $\mathrm{mm}^{3}(46.4 \%$ vs $11.0 \%)$ and $(45.2 \%$ vs $6.6 \%)$, respectively. Related to obstetric complications, the prevalence of low birth weight was $14(63.6 \%), 4(28.6 \%), 12$ $(30.8 \%)$, and the prevalence of preterm delivery was 8 (46.4\%), 5 (35.7\%) and 13 (33.3\%) among those mothers who had anemia, Eclamsia and PROM, respectively (Table 2). 
Table 1. Clinical and current obstetric characteristics of the HIV-infected Women.

\begin{tabular}{|c|c|}
\hline Characteristics & Frequency \\
\hline \multicolumn{2}{|c|}{ HIV disease status and treatment related } \\
\hline \multicolumn{2}{|c|}{ WHO clinical stage $(n=413)$} \\
\hline Stage I & $106(25.70 \%)$ \\
\hline Stage II & $139(33.70 \%)$ \\
\hline Stage III & $97(23.50 \%)$ \\
\hline Stage IV & $71(17.10 \%)$ \\
\hline \multicolumn{2}{|l|}{ CD4 count } \\
\hline \multicolumn{2}{|c|}{ Level $\left(\right.$ cells $\left./ \mathrm{mm}^{3}\right)(\mathrm{n}=387)$} \\
\hline$\leq 200$ & $84(20.20 \%)$ \\
\hline $201-350$ & $122(29.30 \%)$ \\
\hline$>351$ & $181(43.50 \%)$ \\
\hline \multicolumn{2}{|c|}{ HAART exposure $(n=416)$} \\
\hline Yes & $200(48.070 \%)$ \\
\hline No & $216(51.93 \%)$ \\
\hline \multicolumn{2}{|c|}{ Time HAART tarted $(\mathrm{n}=200)$} \\
\hline Before pregnancy & $72(17.30 \%)$ \\
\hline On pregnancy & $128(30.80 \%)$ \\
\hline \multicolumn{2}{|c|}{ PMTCT intervention $(\mathrm{n}=416)$} \\
\hline No & $86(20.70 \%)$ \\
\hline Yes & $330(79.30 \%)$ \\
\hline
\end{tabular}

\begin{tabular}{cc}
\hline \multicolumn{2}{c}{ Current obstetric related factors } \\
\hline Mode of labor $(\mathrm{n}=416)$ & $36(8.70 \%)$ \\
Induced & $380(91.30 \%)$ \\
Spontaneous & \\
Mode of delivery $(\mathrm{n}=416)$ & $346(83.20 \%)$ \\
Spontaneous vaginal & $45(10.80 \%)$ \\
Induced/assisted & $25(6.00 \%)$ \\
Operative & \\
Maternal BMI $(\mathrm{n}=347)$ & $77(22.20 \%)$ \\
$<18.5$ & $270(77.80 \%)$ \\
$\geq 18.5$ & \\
Obstetric complications $(\mathrm{n}=416)$ & $20(4.80 \%)$ \\
APH & $22(5.20 \%)$ \\
Anemia & $14(3.40 \%)$ \\
Eclamsia & $39(9.40 \%)$ \\
PROM & $311(74.80 \%)$ \\
None & \\
Memale & $192(46.20 \%)$ \\
Sex of the infant $(\mathrm{n}=416)$ & $224(53.80 \%)$ \\
\hline
\end{tabular}

Table 2. Prevalence of LBW and PD among infants born to HIV-positive mothers

\begin{tabular}{|c|c|c|}
\hline Factors & $\begin{array}{l}\text { Low birth weight } \\
\qquad(\mathrm{n}=89)\end{array}$ & $\begin{array}{c}\text { Preterm } \\
\text { delivery }(n=69)\end{array}$ \\
\hline & Frequency $(\%)$ & Frequency $(\%)$ \\
\hline \multicolumn{3}{|l|}{ Age of mother } \\
\hline$<20$ & $1(1.10)$ & $1(1.40)$ \\
\hline $20-25$ & $35(39.40)$ & $28(40.60)$ \\
\hline $26-30$ & $36(40.40)$ & $28(40.60)$ \\
\hline$>30$ & $17(19.10)$ & $12(17.40)$ \\
\hline \multicolumn{3}{|l|}{ Residence } \\
\hline Urban & $77(86.40)$ & $59(85.50)$ \\
\hline Rural & $12(13.60)$ & $10(14.50)$ \\
\hline \multicolumn{3}{|l|}{ Educational status } \\
\hline Uneducated & $40(44.90)$ & $33(47.80)$ \\
\hline Primary school & $30(33.70)$ & $24(34.70)$ \\
\hline Secondary school & $11(12.50)$ & $9(13.20)$ \\
\hline Tertiary/College & $8(8.90)$ & $3(4.30)$ \\
\hline \multicolumn{3}{|l|}{ Maternal occupation } \\
\hline Housewife & $46(51.70)$ & $40(58.00)$ \\
\hline Daily laborer & $24(27.00)$ & $19(27.70)$ \\
\hline Merchant & $5(5.70)$ & $3(4.30)$ \\
\hline Local drinking seller & $2(2.20)$ & $1(1.40)$ \\
\hline Gov't employee & $7(7.80)$ & $3(4.30)$ \\
\hline No/dependant & $5(5.60)$ & $3(4.30)$ \\
\hline \multicolumn{3}{|l|}{ Marital status } \\
\hline Single & $11(12.30)$ & $6(8.60)$ \\
\hline Married & $47(52.80)$ & $41(59.60)$ \\
\hline Divorced & $19(21.30)$ & $14(20.30)$ \\
\hline Widowed & $6(6.70)$ & $5(7.20)$ \\
\hline Separated & $6(6.70)$ & $3(4.30)$ \\
\hline \multicolumn{3}{|l|}{ Pregnancy history } \\
\hline Primi-gravida & $29(32.60)$ & $23(33.30)$ \\
\hline Multi-gravida & $60(67.40)$ & $44(63.70)$ \\
\hline \multicolumn{3}{|l|}{ Obstetric complications } \\
\hline None & $56(63.50)$ & $40(58.00)$ \\
\hline APH & $2(2.40)$ & $2(2.80)$ \\
\hline Anemia & $14(15.70)$ & $8(11.60)$ \\
\hline Eclamsia & $4(4.60)$ & $5(7.20)$ \\
\hline PROM & $12(13.80)$ & $13(18.80)$ \\
\hline \multicolumn{3}{|l|}{ BMI } \\
\hline$<18.499$ & $43(55.80)$ & $34(44.20)$ \\
\hline
\end{tabular}




\section{Continued}

\begin{tabular}{|c|c|c|}
\hline$>18.5$ & $40(14.80)$ & $27(10.00)$ \\
\hline \multicolumn{3}{|l|}{ Infections/OIs } \\
\hline STI & $9(10.10)$ & $10(14.50)$ \\
\hline Tuberculosis & $9(10.10)$ & $11(15.90)$ \\
\hline UTI & $10(11.20)$ & $10(14.50)$ \\
\hline Chronic diarrhea & $7(7.80)$ & $4(5.70)$ \\
\hline None & $54(60.80)$ & $34(49.40)$ \\
\hline \multicolumn{3}{|l|}{ PMTCT intervention } \\
\hline No & $79(88.70)$ & $45(65.20)$ \\
\hline Yes & $10(11.30)$ & $24(37.80)$ \\
\hline \multicolumn{3}{|l|}{ HAART exposure } \\
\hline No & $12(13.50)$ & $25(36.20)$ \\
\hline Yes & $77(86.50)$ & $44(63.80)$ \\
\hline \multicolumn{3}{|l|}{ Time HAART initiated } \\
\hline Before pregnancy & $44(49.40)$ & $22(31.90)$ \\
\hline On pregnancy & $33(37.10)$ & $22(31.90)$ \\
\hline None & $12(13.50)$ & $25(36.20)$ \\
\hline \multicolumn{3}{|l|}{$\mathrm{ARV}$ intervention } \\
\hline None & $10(11.30)$ & $24(34.90)$ \\
\hline HAART & $77(86.50)$ & $44(63.60)$ \\
\hline Prophylaxis & $2(2.20)$ & $1(1.50)$ \\
\hline \multicolumn{3}{|l|}{ CD4 level (cell//mm³) } \\
\hline$<200$ & $39(43.80)$ & $38(55.10)$ \\
\hline $201-350$ & $30(33.70)$ & $19(27.50)$ \\
\hline$>351$ & $20(22.50)$ & $12(17.40)$ \\
\hline \multicolumn{3}{|l|}{ WHO clinical stage } \\
\hline I & $14(15.70)$ & $7(10.20)$ \\
\hline II & $17(19.10)$ & $10(14.50)$ \\
\hline III & $33(37.10)$ & $29(42.00)$ \\
\hline IV & $25(28.10)$ & $23(33.30)$ \\
\hline \multicolumn{3}{|l|}{ Gestational age at birth } \\
\hline$\geq 37$ weeks & $24(27.00)$ & \\
\hline$<37$ weeks & $65(73.00)$ & \\
\hline \multicolumn{3}{|l|}{ Mode of labor } \\
\hline Induced & $5(5.60)$ & $6(8.70)$ \\
\hline Spontaneous & $84(94.40)$ & $63(91.30)$ \\
\hline \multicolumn{3}{|l|}{ Mode of delivery } \\
\hline Spontaneous vaginal & $77(86.50)$ & $56(81.10)$ \\
\hline Assisted/instrumental & $8(9.00)$ & $8(11.60)$ \\
\hline Operative & $4(4.50)$ & $5(7.30)$ \\
\hline
\end{tabular}

APH, Antepartum Hemorrhage; PROM, Premature Rupture of Membrane; PD, Preterm Delivery; LBW, Low Birth Weight; OIs, Opportunistic Infections.

\subsection{Factors Associated with Low Birth Weight and Preterm Delivery}

The Univariate analysis showed that maternal baseline WHO clinical stage of disease, advanced baseline WHO clinical stage (stage III and IV) $(\mathrm{p} \leq 0.001)$ and maternal obstetric related complications (anemia, Eclamsia and PROM) $(\mathrm{p} \leq 0.001)$ were significantly associated with LBW and PD. Maternal exposure to HAART during pregnancy showed two times more likely to increase the risk of preterm delivery as compared to those who had started before conception.

The multivariate analysis (Tables 3 and 4 ) of factors associated with LBW indicated that mothers who had a CD4 count level below 200 cells $/ \mathrm{mm}^{3}$ had 4.2 times higher risk of having LBW as compared to those with CD4 level above 350 cells $/ \mathrm{mm}^{3}$. As compared to those who were not exposed to HAART, mothers who were taking HAART during pregnancy had 8.2 fold increased risk of having LBW. In addition, maternal BMI below 18.5 and maternal anemia were significantly associated with LBW.

On the other hand, mothers who had no PMTCT intervention had 1.53 times higher risk of having preterm birth as compared to those mothers who had PMTCT intervention. Moreover, mothers who had started HAART before pregnancy had 1.82 fold increased risk of having PD as compared with those mothers who started on pregnancy. Baseline maternal CD4 level below $200 / \mathrm{mm}^{3}$, maternal Eclamsia during pregnancy and maternal BMI less than 18.5 were also significantly associated with PD.

\section{DISCUSSION}

This study showed that, there were significant adverse birth outcomes including high rate of LBW and PD among infant born to HIV-positive women in the study area. The rate of LBW and PD were higher than the total prevalence in the general population in Ethiopia (11\%) [5]. It is also by far higher than previous studies conducted in the general population in Addis Ababa [27] and Gondar hospital [28]. The difference however may be due to the current study included only the HIV-infected women.

The current prevalence of LBW is almost comparable to that of study conducted in South Africa 22\% [22], Ghana (22.5\%) [29], and China (19.6\%) [19]. However, the rate of PD was higher than the report of a study from China (9.8\%) [19] and Thailand (10.2\%) [30], but lower than study from Ghana [29] which is $(24.4 \%)$. The differences may be due to either the maternal treatment for the HIV (PMTCT services), or the study setting including Socio-demographic factors of the mothers and the time gap between the studies. 


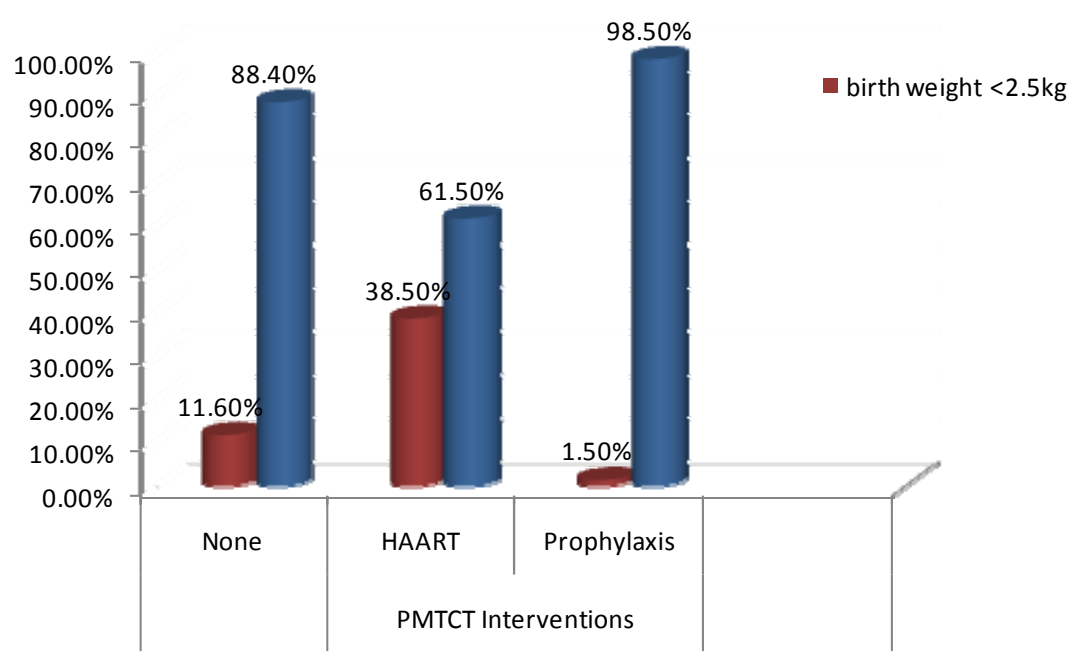

Figure 2. Prevalence of low birth weight by the type of PMTCT interventions taken by the mothers during pregnancy.

Table 3. Bivariate and multivariate analysis of associated factors for low birth weight among infants born to HIV-infected women $(\mathrm{n}=386)$

\begin{tabular}{|c|c|c|c|c|}
\hline \multirow[t]{2}{*}{ Factors } & \multicolumn{2}{|c|}{ LBW } & \multicolumn{2}{|c|}{ OR (95\% CI) } \\
\hline & Yes & No & Unadjusted OR & Adjusted OR \\
\hline \multicolumn{5}{|l|}{$\begin{array}{l}\text { Maternal } \\
\text { CD4 level }\end{array}$} \\
\hline \multicolumn{5}{|c|}{$\left(\right.$ cells/mm $\left./ \mathbf{m m}^{3}\right)$} \\
\hline$<20$ & 39 & 45 & $6.97[3.70-13.13]$ & $4.24[1.85-9.69]^{*}$ \\
\hline $201-350$ & 30 & 92 & $2.62[1.41-4.88]$ & $1.13[0.53-2.37]$ \\
\hline$>351$ & 20 & 161 & 1.0 & 1.0 \\
\hline \multicolumn{5}{|c|}{$\begin{array}{l}\text { Maternal WHO } \\
\text { clinical stage }\end{array}$} \\
\hline Stage I & 14 & 92 & 1.0 & \\
\hline Stage II & 17 & 122 & $0.91[0.42-1.95]$ & \\
\hline Stage III & 33 & 64 & $3.38[1.68-6.83]^{*}$ & \\
\hline Stage IV & 25 & 46 & $3.57[1.69-7.51]^{*}$ & \\
\hline \multicolumn{5}{|c|}{ Maternal BMI } \\
\hline$<18.499$ & 43 & 34 & $7.27[4.14-12.74]$ & $5.50[2.82-10.74]^{*}$ \\
\hline$>18.5$ & 40 & 230 & 1.0 & 1.0 \\
\hline \multicolumn{5}{|l|}{$\begin{array}{l}\text { HAART } \\
\text { exposure }\end{array}$} \\
\hline No & 12 & 204 & 1.0 & 1.0 \\
\hline Yes & 77 & 123 & $10.64[5.56-20.34]$ & $8.26[2.53-14.34]^{*}$ \\
\hline \multicolumn{5}{|c|}{$\begin{array}{c}\text { Obstetric } \\
\text { complications }\end{array}$} \\
\hline None & 56 & 255 & 1.0 & 1.0 \\
\hline APH & 2 & 18 & $0.50[0.11-2.24]$ & $0.001[0.007-1.67]$ \\
\hline Anemia & 14 & 8 & $7.96[3.19-19.90]^{*}$ & $5.52[1.62-15.85]^{*}$ \\
\hline Eclamsia & 4 & 10 & $1.82[0.55-6.01]$ & $0.20[0.001-3.67]$ \\
\hline PROM & 12 & 27 & $2.02[0.96-4.23]$ & $0.74[0.003-2.04]$ \\
\hline
\end{tabular}

* ${ }^{*}$ significant.
Advanced maternal HIV disease is recognized as risk factor for LBW and PD according to the report of many studies $[15,31,32]$. Studies from Kenya also showed that HIV-infected women were 3 times more likely to deliver a LBW baby in the presence of HIV-related symptoms and lower CD4 level $[33,34]$. The Univariate analysis in this study indicated that advanced maternal WHO clinical stage, especially in advanced WHO clinical stage III $(\mathrm{p} \leq 0.0001)$ and stage IV $(\mathrm{p} \leq 0.0001)$ were associated with LBW and PD, even though this variable didn't persist in the multivariate analysis .

Mothers, especially those whose baseline CD4 level was below 200 cells $/ \mathrm{mm}^{3}$ had 4.24 times higher risk of getting LBW than those CD4 above 350 cells $/ \mathrm{mm}^{3}$. This can be explained by the fact that mothers who were in advanced clinical stage might also faced severe cases of opportunistic infections or HIV related symptoms which affect the mothers' health, nutritional status and the inutero fetal growth. This is supported by similar study which have showed that women with a CD4 count $<200$ cells $/ \mathrm{ml}$ were nearly twice as likely to have an adverse pregnancy outcome than those with a CD4 count of 500 cells $/ \mathrm{ml}$ or more $[19,23]$. However, other study revealed that there was no difference in LBW and PD among cohorts of mothers with $<200$ CD4 cells and $>500$ CD4 cells [35].

On the other hand, mothers who were on HAART had 8.2 fold increased risk of having LBW compared to their counterparts. But, our study didn't compare birth weight outcome with the respective time at which HAART was initiated during pregnancy; and we thus declare that the higher risk of LBW may not be due to the HAART itself, but the women may have faced severe forms of the disease or immunosuppression or in chronic illness. This finding is consistent with other previous studies [22,30] 
Table 4. Bivariate and multivariate analysis of associated factors of preterm delivery (PD) among infants born to HIV-infected women $(\mathrm{n}=386)$.

\begin{tabular}{|c|c|c|c|c|}
\hline \multirow[t]{2}{*}{ Factors } & \multicolumn{2}{|c|}{ PD } & \multicolumn{2}{|c|}{ OR (95\% CI) } \\
\hline & Yes & No & Unadjusted OR & Adjusted OR \\
\hline \multicolumn{5}{|l|}{$\begin{array}{l}\text { CD4 level } \\
\left.\text { (cells/mm } \text { mm }^{3}\right)\end{array}$} \\
\hline$<200$ & 38 & 46 & $11.63[5.62-24.05]$ & $5.37[1.86-15.49]^{*}$ \\
\hline $201-350$ & 19 & 103 & $2.59[1.21-5.57]$ & $0.83[0.28-2.41]^{*}$ \\
\hline$>351$ & 12 & 169 & 1.0 & 1.0 \\
\hline \multicolumn{5}{|l|}{$\begin{array}{l}\text { WHO clinical } \\
\text { stage }\end{array}$} \\
\hline Stage I & 7 & 99 & 1.0 & \\
\hline Stage II & 10 & 129 & 1.09 [0.40 - 2.99] & \\
\hline Stage III & 29 & 68 & $6.03[2.49-14.55]^{*}$ & \\
\hline Stage IV & 23 & 48 & $6.77[2.71-16.89]^{*}$ & \\
\hline \multicolumn{5}{|l|}{ Maternal BMI } \\
\hline$<18.499$ & 34 & 43 & $7.11[3.90-12.97]$ & $4.52[2.39-9.27]^{*}$ \\
\hline$>18.5$ & 27 & 243 & 1.0 & 1.0 \\
\hline \multicolumn{5}{|l|}{$\begin{array}{c}\text { Time HAART } \\
\text { initiated }\end{array}$} \\
\hline Before pregnancy & 22 & 50 & $2.12[1.07-4.18]$ & $1.82[1.02-3.81]^{*}$ \\
\hline On pregnancy & 22 & 106 & 1.0 & 1.0 \\
\hline \multicolumn{5}{|l|}{$\begin{array}{c}\text { Obstetric } \\
\text { complications }\end{array}$} \\
\hline None & 40 & 271 & 1.0 & 1.0 \\
\hline APH & 2 & 18 & $0.75[0.16-3.36]$ & $0.021[0.001-2.83]$ \\
\hline Anemia & 8 & 14 & $3.87[1.52-9.81]^{*}$ & $2.45[0.71-7.71]$ \\
\hline Eclamsia & 5 & 9 & $3.76[2.82-11.79]^{*}$ & $2.03[1.51-9.52]^{*}$ \\
\hline PROM & 13 & 26 & $3.38[1.61-7.12]^{*}$ & $2.05[0.82-5.83]$ \\
\hline \multicolumn{5}{|l|}{$\begin{array}{c}\text { PMTCT } \\
\text { intervention }\end{array}$} \\
\hline No & 24 & 62 & $2.45[1.39-4.32]^{*}$ & $1.53[1.24-3.05]^{*}$ \\
\hline Yes & 45 & 285 & 1.0 & 1.0 \\
\hline \multicolumn{5}{|l|}{ HAART exposure } \\
\hline No & 25 & 191 & 1.0 & \\
\hline Yes & 44 & 156 & $2.15[1.26-3.67]^{*}$ & \\
\hline
\end{tabular}

"significant, COR, Crude Odds Ratio; AOR, Adjusted Odds Ratio; CI, Confidence Interval.

suggesting that, mothers who received HAART during pregnancy had 2.27 times higher risk of getting LBW. Similarly studies conducted in Poland [36], Côte d'Ivoire [37] and Botswana [20] have indicated the higher risk of
LBW and PD among HAART-exposed mothers during pregnancy.

Poor maternal nutrition coupled with the chronic illness may be associated with an adverse birth outcome in HIV-infected women. The multivariate analysis of the current study found out 5.5 and 4.5 times higher risk of LBW and PD, respectively among mothers whose BMI was below 18.5. Moreover, maternal anemia has increased the rate of LBW by 5.5 fold. This finding is supported by a similar study which revealed that mothers whose BMI was below 21.8 had 1.82 times higher risk of having PD and 2.09 times higher risk of LBW [38].

Mothers who had no PMTCT/untreated pregnancy infection had 1.53 fold higher risk of having preterm delivery compared to the treated group. A study conducted in Nigeria [39] also revealed that PDs were significantly higher among women with untreated-HIV infection in pregnancy compared with women who received HAART or prophylaxis at early pregnancy. This could be due to high chance of occurrence of infections burden on the mother if untreated. This suggests the need for further strengthening of PMTCT intervention programme to decrease pregnancy complications.

This study also reported that women who were already on HAART preconception had 1.82 fold increased risk of having PD compared to those who started on pregnancy. In line with this a study conducted by European collaborative team observed a 2.1 -fold increased risk when HAART was started preconception $[21,40,41]$, and the risk of delivery before 34 weeks of gestation was 4.4fold for those entering pregnancy on combination ARV regimens [40]. A study conducted in Poland [36] also revealed that Preterm deliveries were highly prevalent among women on HAART during pregnancy, especially when therapy was started before or in the first trimester of pregnancy.

The findings of this study had limitations. Owing to its design, and as the study was conducted within routine clinical settings, the study were unfortunately not able to assess other known risk factors which might also be associated with LBW and PD like family income; and maternal smoking and alcohol intake history during pregnancy though these are not common culture among Ethiopian women in the study area. The study focuses only on the HIV-infected pregnant women. This implies that no conclusions can be drawn with regard to the influence of HIV per se on birth outcomes unless the HIV-negative control group is involved. In addition, the fact that the data used were secondary there may be bias and missing or incomplete informations. Our study is hospital based, and there might be mothers who gave birth at home; and we declare that this study result may not represent all the HIV positive pregnant women. 


\section{CONCLUSION AND RECOMMENDATION}

This study has highlighted that adverse infant birth outcome, the rate of low birth weight and preterm delivery among HIV-positive pregnant mother were unacceptably high compared to the national report.

The finding of this study also suggested that low maternal baseline CD4 count level, low maternal BMI, preterm delivery and maternal HAART exposure were associated risk factors for low birth weight. On the other hand, low baseline maternal CD4 count level, lack of PMTCT intervention/untreated HIV infection, low maternal BMI, and mothers being on HAART pre-pregnancy were associated with preterm delivery.

Based on the finding of this study the regional and zonal health department and health facilities should consider and give focus on the following recommendations:

- The earlier identification and treatment of mothers before their conception to delay conception until CD4 cell count increased and HIV viral load decrease, especially in those in advanced clinical stage.

- Encouraging and educating severely immuno-compromised HIV-infected women who plan to become pregnant to wait until immune restoration may help to reduce the risk of LBW and PD.

- Family planning programme should be more strengthened, giving special attention to HIV-infected mothers especially who are on HAART and in advanced clinical stage to delay pregnancy.

- Strengthening education and nutritional supplementation for HIV infected mothers.

- Strengthening PMTCT services not to miss treatment for all HIV-infected women having the intention to have children.

\section{ACKNOWLEDGEMENTS}

We would like to extend our heartfelt thanks to the University of Gondar for financing this study. We would also like to appreciate Gondar University Hospital staff, Metema and Debark Hospitals medical directors and staff, I tech. Ethiopia Office for allowing us to access data and other staff for their support during data collection, data base access and data collection assistants.

\section{REFERENCES}

[1] UNAIDS WHO (2009) AIDS epidemic update. World Health Organization.

[2] UNAIDS/WHO (2008) Report on the Global AIDS Epidemic. World Health Organization, Geneva.

[3] UNAIDS 2012 Report: Regional Fact Sheet.

[4] The United States President's Emergency Plan for HIV/ AIDS Relief, Ethiopia Country Operational Plan 2007, April, 2007.
[5] Central Statistical Agency [Ethiopia] and ICF International (2012) Ethiopia Demographic and Health Survey 2011. Central Statistical Agency and ICF International, Addis Ababa, Ethiopia and Calverton, Maryland.

[6] Federal HIV/AIDS Prevention and Control Office (2011) Prevention of Mother to Child Transmission 2010. http://www.etharc.org/

[7] Tilahun Nigatu, Y.W. (2011) Analysis of the Prevention of Mother-to-Child Transmission (PMTCT) service utilization in Ethiopia: 2006-2010. Reproductive Health, 8, 6. http://wwwreproductive-health-journalcom/content/8/1/6

[8] World Health Organization (2010) Antiretroviral drugs for treating pregnant women and preventing hiv infection in infants. Recommendations for a Public Health Approach, World Health Organization.

[9] WHO (2010) Towards universal access: Scaling up priority HIV/AIDS interventions in the health sector. Progress Report.

http://www.who.int/hiv/pub/2010progressreport/report/en /index.html

[10] Towards Universal Access Progress. http://www.who.int/hiv/pub/2009progressreport/en/

[11] Hargrove, J.W. and Humphrey, J.H. (2010) ZS G: Mortality among HIV-positive postpartum women with high CD4 cell counts in Zimbabwe. AIDS, 24, F11-F14. doi:10.1097/QAD.0b013e328335749d

[12] Kourtis, A.P. (2010) Antiretroviral drug use during pregnancy and risk of premature delivery: Is there a connection? The Journal of Infectious Diseases, 201, 978-980. doi: $10.1086 / 651233$

[13] Patrice Tchendjou, C.S.-E., Annie, N., Mathurin, T., Anfumbom, K., Anne, N.N., Landry, T., Anne, C.B., Daniel, E., Joanna, O.-G., Dominique, R., Regis, P. and Francois, D. (2010) Effectiveness of multidrug antiretroviral regimens to prevent mother-to-child transmission of HIV-1 in routine public health services in Cameroon. PLOS ONE, 5.

[14] Hoosen, C. (2004) Antiretroviral agents-How best to protect infants from HIV and save their mothers from AIDS. New England Journal of Medicine, 351, 289-292. doi:10.1056/NEJMe048128

[15] Kourtis, A.P.S.C., Jamieson, D.J. and Lau, J. (2007) Use of antiretroviral therapy in pregnant HIV-infected women and the risk of premature delivery: A meta-analysis. AIDS, 21, 607-615. doi:10.1097/QAD.0b013e32802ef2f6

[16] Nigel, C., Rollins, H.M.C., et al. (2007) Pregnancy outcomes in HIV-infected and uninfected women in rural and urban South Africa. Journal of Acquired Immune Deficiency Syndromes, 44, 321-328. doi:10.1097/QAI.0b013e31802ea4b0

[17] Denise Naniche, A.B., María, L., Anna, B., Inacio, M., Sergi, S., John, J.A., Betuel, S, Pedro, L.A. and Clara, M. (2009) Impact of maternal human immunodeficiency virus infection on birth outcomes and infant survival in rural Mozambique. The American Journal of Tropical Medicine and Hygiene, 80, 870-876.

[18] Federal HIV/AIDS Prevention and Control Office (2007) Guidelines for prevention of mother-to-child transmission 
of HIV in Ethiopia.

[19] Yu, L., Li, W.Y., Chen, R.Y., Tang, Z.R., Pang, J., Gui, X.Z., Meng, X.N. and Zhang, F.J. (2012) Pregnancy outcomes and risk factors for low birth weight and preterm delivery among HIV-infected pregnant women in Guangxi, China. Chinese Medical Journal, 125, 403-409.

[20] Chen, J. (2009) Risk factors for adbverse pregnancy outcomes among HIV infected women in Gaborone, Botswana. 16th Conference on Retroviruses and Opportunistic Infections, Montreal, 2009.

[21] Machado, E.S.H.C., Costa, T.T., et al. (2009) Pregnancy outcome in women infected with HIV-1 receiving combination antiretroviral therapy before versus after conception. Sexually Transmitted Infections, 85, 82-87. doi:10.1136/sti.2008.032300

[22] Karin van der Merwe, R.H., Vivian, B., Matthew, C., Ashraf, C. and Helen, R. (2011) Birth outcomes in South African women receiving highly active antiretroviral therapy: A retrospective observational study. Journal of the International AIDS Society, 14, 42.

[23] Rollins, N.C.C.H., Bland, R.M., Coutsoudis, A., Bennish, M.L., Patel, D. and Newell, M.L. (2007) Pregnancy outcomes in HIV infected and uninfected women in rural and urban South Africa. Journal of Acquired Immune Deficiency Syndromes, 44, 321-328. doi:10.1097/QAI.0b013e31802ea4b0

[24] Langston, C.L.D., Hammill, H.A., Popek, E.J., Kozinetz, C.A., Kline, M.W., Hanson, I.C. and Shearer, W.T. (1995) Excess intrauterine fetal demise associated with maternal human immunodeficiency virus infection. The Journal of Infectious Diseases, 172, 1451-1460. doi:10.1093/infdis/172.6.1451

[25] United Nations Children's Fundand World Health Organization (2004) Low birth weight: Country, regional and global estimates. UNICEF, New York.

[26] (2012) Care of the preterm and/or low-birth-weight newborn.

http://www.who.int/maternal_child_adolescent/topics/ne wborn/care_of_preterm/en/

[27] Tegegne, B.A., Enquoselassie, F. and Yusuf, L. (2010) Birth to pregnancy interval and its effect on perinatal outcomes in Addis Ababa, Ethiopia. Ethiopian Journal of Reproductive Health, 4, 37-51.

[28] Megabiaw, B., Zelalem, M. and Mohammed, N. (2012) Incidence and correlates of low birth weight at a referral hospital in Northwest Ethiopia. The Pan African Medical Journal, 12, 14.

[29] Laar, A.K., Ampofo, W., Tuakli, J.M., Norgbe, G.K. and Quakyi, I.A. (2010) Preterm delivery and low birth weight among neonates born to HIV-positive and HIV-negative Ghanaian women. Journal of Public Health and Epidemiology, 2, 224-237.

[30] Darin Areechokchai, C.B., Benjaluck, P., Punnee, P. and Wirach, M.-a-N. (2009) Pregnancy outcomes among HIVinfected women undergoing antiretroviral therapy. The Open AIDS Journal, 3, 8-13.
[31] Stratton, P.T.R., Abboud, R., et al. (1999) Obstetric and newborn outcomes in a cohort and HIV-infected pregnant women: A report of the women and infants transmission study. Journal of Acquired Immune Deficiency Syndromes and Human Retrovirology, 20, 179-186. doi:10.1097/00042560-199902010-00011

[32] Powis, K.M., Kitch, D., Ogwu, A., Hughes, M.D., Lockman, S., Leidner, J., Widenfelt, E., Moffat, C., Moyo, S., Makhema, J. et al. (2011) Increased risk of preterm delivery among HIV infected women randomized to protease versus nucleoside reverse transcriptase inhibitor-based HAART during pregnancy. Journal of Infectious Diseases, 204, 506-514. doi:10.1093/infdis/jir307

[33] Braddick, M.R.K.J., Embree, J.B., et al. (1990) Impact of maternal HIV infection on obstetrical and early neonatal outcome. AIDS, 4, 1001-1005. doi:10.1097/00002030-199010000-00009

[34] Katia Kastetbon, J.L., Valeriane, L. et al. (1999) Low birth weight in infant born to African HIV-infected Women: Relationship with maternal body weight during pregnancy. Journal of Tropical Pediatrics, 45.

[35] The Kesho Bora Study Group (2010) Eighteen-month follow-up of HIV-1 - Infected mothers and their children enrolled in the kesho bora study observational cohorts. Journal of Acquired Immune Deficiency Syndrome, 54, 533-541.

[36] Kowalska, A.N.T., El Midaoui, A. and Burkacka, E. (2003) Effect of antiretroviral therapy on pregnancy outcome in HIV-1 positive women. Med Wieku Rozwoj, 7, 459-468.

[37] Ekouevi, D.K.C.P., Becquet, R., Tonwe-Gold, B., Horo, A., Thiebaut, R., Leroy, V., Blanche, S., Dabis, F. and Abrams, E.J. (2008) Antiretroviral therapy in pregnant women with advanced HIV disease and pregnancy outcomes in Abidjan, Cote d'Ivoire. Aids, 22, 1815-1820. doi:10.1097/QAD.0b013e32830b8ab9

[38] Mehta, S., Manji, K.P., Young, A.M., Brown, E.R., Chasela, C., Taha, T.E., Read, J.S., Goldenberg, R.L. and Fawzi, W.W. (2008) Nutritional indicators of adverse pregnancy outcomes and mother-to-child transmission of HIV among HIV-infected women. American Journal of Clinical Nutrition, 87, 1639-1649.

[39] Joseph, O., Biodun, O. and Michael, E. (2011) Pregnancy outcome among HIV positive women receiving antenatal HAART versus untreated maternal HIV infection. Journal of College of Physicians and Surgeons Pakistan, 21, 356-359.

[40] Thorne, C.P.D. and Newell, M.L. (2004) For the European collaborative study. Increased risk of adverse pregnancy outcomes in HIV-infected women treated with highly active antiretroviral therapy in Europe. AIDS, 18, 2337-2339. doi:10.1097/00002030-200411190-00019

[41] European Collaborative Study SMaCCS (2000) Combination antiretroviral therapy and duration of pregnancy. AIDS, 14, 2913-2920. doi:10.1097/00002030-200012220-00013 